MIP

39,5

670

Received 23 October 2019

Revised 24 May 2020

9 July 2020

5 October 2020

21 December 2020

Accepted 22 December 2020

\section{Market-oriented business model for SMEs' disruptive innovations internationalization}

\author{
Agneta Sundström, Akmal S. Hyder and Ehsanul Huda Chowdhury \\ Department of Business Studies and Economics, University of Gävle, Gävle, Sweden
}

\begin{abstract}
Purpose - The aim of this study is to develop and evaluate a market-oriented business model (MOBM) and analyze how it contributes to internationalization of SMEs' disruptive innovation.

Design/methodology/approach - Based on market orientation literature, an MOBM is developed and assessed through collaboration among companies, researchers and networking partners. For the evaluation of the model, qualitative data was collected through workshops, interviews and participatory observations at four case SMEs. Methodologically, the implementation of the MOBM consists of a systematic knowledge development process by following four work packages to support the companies' market-oriented internationalization.

Findings - The results show that SMEs face internal barriers to developing innovativeness that hinder them from creating effective disruptive innovation for the international buyer chain. The study finds that SMEs need to work with an MOBM for developing market intelligence within the organization and seek external support for entering the international market.

Practical implications - The methodological strength allows application, evaluation and modification of the MOBM in close collaboration with the SMEs that directly benefit from its implementation. Modifying the principles of market orientation by practical application, SMEs can apply the MOBM to analyze their internationalization capacity for high-tech disruptive innovations.

Originality/value - This article contributes to new thinking by introducing market orientation to SMEs' internationalization of disruptive innovation. The study highlights the less researched field of disruptive innovation by developing the MOBM to deal with SMEs' internationalization.
\end{abstract}

Keywords Market orientation, SMEs, Business model, Disruptive innovation, Internationalization, Buyer chains

Paper type Research paper

\section{Introduction}

Research in market orientation (MO) has had a major influence on analyzing how companies meet customers' needs. According to MO principles, successful companies collect information about customer needs and market conditions, disseminate information in the organization as culture and develop strategies that meet the requirements of the buyers and their buying chain (Kohli and Jaworski, 1990; Narver and Slater, 1990). The studies of Kohli and Jaworski (1990) and Narver and Slater (1990) have contributed to considerable MO research, especially on how to investigate the relationships among issues related to customer needs, cross-sector knowledge, dissemination and innovativeness, strategic responsiveness and implications and impact on business performance. That research, however, has mainly concentrated on examining how larger companies meet market requirements, while small and medium-size

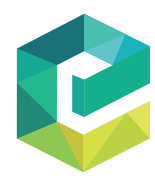

(C) Agneta Sundström, Akmal S. Hyder and Ehsanul Huda Chowdhury. Published by Emerald Publishing Limited. This article is published under the Creative Commons Attribution (CC BY 4.0) licence. Anyone may reproduce, distribute, translate and create derivative works of this article (for both commercial and non-commercial purposes), subject to full attribution to the original publication and authors. The full terms of this licence may be seen at http://creativecommons.org/licences/by/4.0/ legalcode

Funding: This research is funded by the European Regional Development Fund (ERDF).
Marketing Intelligence \& Planning Vol. 39 No. 5,2021 pp. $670-686$ Emerald Publishing Limited 0263-4503

DOI 10.1108/MIP-10-2019-0527 
companies' (SMEs) adaptation to international conditions has received scant interest. Furthermore, few studies have drawn attention to how SMEs that have developed disruptive innovation can apply MO principles as part of their business model to streamline the internationalization process - a research gap this study aims to fill.

The growing recognition that disruptive innovation is a competitive strategic tool for market orientation has allowed researchers to prioritize it as a research focus (Rasool et al., 2018). The market orientation of disruptive innovation by SMEs has, however, received almost no research attention (Cowden and Alhorr, 2013), for several reasons. First, this is a long-term, strategic and highly risky process for SMEs to manage, involving collecting knowledge of the market to facilitate the introduction of new ideas. Christensen and Bower (1996) state that failure in entering new markets is caused by managerial myopia, organizational lethargy or insufficient expertise. Second, the originality of the innovation per se makes customer values difficult to influence and change rapidly. Third, that any change of technologies is influenced by a locked-in resistance to change, especially when change threatens incumbent business innovation systems (Cowden and Alhorr, 2013). This paper adds a fourth reason and research gap: the lack of an international market orientation business model (MOBM) helping SMEs to manage what Schmidt and Druehl (2008) call the encroachment from high-end customers on low-end customers' needs.

According to Christensen et al. (2015), market complexity demands good knowledge, learning capacity and targeted market strategies, which implies a need for critical resources that SMEs usually lack. In recent years, research has increasingly drawn attention to SMEs' need to receive support from business models (BM) that are adapted to their specific needs and market conditions. BMs help companies take proactive steps to anticipate, address and drive changes toward the international market in a more structured way, to make market orientation more efficient. Nevertheless, BMs must meet certain basic requirements ( $\mathrm{Yu}$ and Hang, 2010). They need to improve knowledge development from top management to the team level; create an organizational culture that supports innovation; improve knowledge about contextual and environmental factors and improve their customer orientation work. Yu and Hang (2010) found that the success of disruptive innovation commonly depends on the companies' knowledge of contextual factors related to the regulatory, normative and economic conditions specific to the international market. Rissanen et al. (2019), however, notice that BMs usually do not take internationalization into account, although the models can act as disruptive by supporting the development and exploration of international business opportunities. We suggest that this process can be made more resource-effective by applying an MOBM framework, tailored to the international market conditions SMEs' business strategies expect to meet. Traditional internationalization research claims that companies must be in the market to acquire necessary knowledge (Johanson and Vahlne, 2009). With global and digital development, along with the support of research and partner collaborations, we argue that SMEs can instead develop international MO knowledge before they physically enter international markets.

The aim of this study is to develop and evaluate an MO-based business model and analyze how it contributes to SMEs' disruptive innovation internationalization. To fulfill this aim, three research questions are addressed:

(1) How can a theoretically based market-oriented business model (MOBM) be developed, applied and revised based on the actual needs of SMEs?

(2) What knowledge requirements need to be developed in SMEs to meet the market needs for disruptive innovations?

(3) How can an MOBM help to manage the challenges SMEs face in the internationalization of disruptive innovations? 
MIP

39,5

This article contributes to new thinking by connecting market orientation to SMEs' internationalization of disruptive innovation research. Although disruptive innovation research commonly is discussed from a market perspective, few studies have so far focused on how the principles of market orientation can be used to support SMEs' internationalization of these innovations. We emphasize that companies need to develop MO knowledge at different value change stages in order to achieve disruptive innovations; buyers do not operate independently anymore but rather as members of chains that can be referred to as buyer chains (Mesic et al., 2018).

\section{Theoretical discussion and research framework}

This study applies the MO approach and connects it with theoretical perspectives of disruptive innovation in the development of an MOBM that can contribute to the internationalization of SMEs. The MO intelligence perspective primarily focuses on how market knowledge is developed, internally disseminated and responded to in order to meet and preferably exceed customer values and needs. The disruptive innovation perspective, on the other hand, focuses on understanding the specifics of the innovation, its context and its ability to thrive in new markets relative to incumbent innovations. Together these two perspectives provide improved understanding of what market-oriented knowledge a disruptive innovation firm must acquire to succeed in new international markets. Finally, we discuss a business model that serves as a support element for SMEs to develop MO knowledge.

\section{Market orientation research}

The studies of Kohli and Jaworski (1990) and Narver and Slater (1990) have contributed to considerable MO research, especially on how to investigate the relationships among knowledge development of customer needs, cross-sector knowledge and dissemination, strategic responsiveness and implications and impact on business performance. In this article, business performance represents the effects of how SMEs, by following the MO intelligence principles, can meet the needs of buyers in the international market.

Kohli and Jaworski (1990) MO perspective is founded in how business attitudes can be changed by developing market intelligence. Their discussion concerns how company-wide intelligence can develop based on the generation and dissemination of market information and organizational responsiveness to this information. Special attention is paid to how organizations collect information concerning customer needs, desires and demands, as well as how mediators (facilitators) and moderators (environmental circumstances) affect business performance (Liao et al., 2011). Forceful companies are assumed to integrate MO into the organization as an intelligent mindset. This implies that a company's responsiveness to collected market information regarding consumer needs reflects the company's tendency, flexibility and ability to act successfully based on what the market wants and requires (Kohli and Jaworski, 1990; Sundström et al., 2016a; Hyder, 2016).

Since market orientation is context-dependent, moderating external factors can greatly influence the MO performance relationship. Market turbulence, competitive or collaborative environment, legal conditions, and economic standing are examples of external contingencies directly affecting this relationship (Kohli and Jaworski, 1990, p. 14; Ahmadi and Sundström, 2017). Even if a company operates in accordance with the MO principles, factors outside the organization can directly affect the results of market initiatives conducted, which can have a special impact on companies with disruptive innovations.

Much research attention is directed to understanding the mediating factors that promote the development of market intelligence representing a company's innovation capability. 
Commonly mentioned mediating factors are learning capacity, management of human resources and implementation issues aimed to improve business performance (Liao et al., 2011). Narver and Slater (1990) have a long-term MO perspective, focusing on cultural aspects of an organization and how these help to create superior customer value. Companies manage interfunctional coordination of core activities to develop a consumer-oriented, innovative business culture. As customers commonly lack insight into what they really want, Slater and Narver (1998) suggest that firms need to develop a culture characterized by innovativeness that moves beyond purely customer-led wants. Instead of claiming to be market-driven, companies have to develop strategies to be market-driving (O'Cass and Ngo, 2007). Narver et al. (2004) criticize the intelligence perspective as representing an outside-in procedure focusing on customers' present needs, whereas their innovativeness and cultural-driven approach represents an inside-out process that builds up companies' own capabilities. They see innovative companies as those that "continuously create superior customer value by sharing the knowledge broadly throughout the organization and by acting in a coordinated manner" (Slater and Narver, 1998, p. 1003).

According to Christensen et al. (2015), market complexity demands good knowledge, learning capacity and targeted market strategies. Innovativeness-focused research especially pays attention to the need to acquire market knowledge and developing strategies to improve product development (Miller and Friesen, 1978). Whereas innovation commonly refers to new products, services, production processes, organizational structure or administrative systems (Hult et al., 2004), innovativeness symbolizes an organization's entrepreneurial capabilities and cultural orientation toward the market (Liao et al., 2011). Sundström et al. (2016a) noticed, however, that no obvious link between innovation and innovativeness exists. Companies can develop innovations driven by external expert demands without having developed the necessary internal capacity built on innovativeness. Urbano et al. (2019) argue that access to resources, appropriate organizational structure and strategies to ensure capacity building of employees through training influence firms' innovativeness. While focusing too much on innovation, companies can underestimate the importance of understanding customer needs and willingness to buy.

Innovativeness can be defined as an organizational ability to attain new thinking and openness to new ideas and how to implement learning capacity (Hult et al., 2004; Bose, 2016). Innovativeness influences developing knowledge of the market via market research, advertising and promotion (Miller and Friesen, 1978), which requires strategic planning, knowledge and openness to new organizational solutions and ideas (Hult et al., 2004; Urbano et al., 2019). According to Zehir et al. (2011), innovativeness could be seen as a systems-based, firm-wide orientation related to innovations. Far-seeing, innovative firms understand how to develop knowledge-based structures consisting of organization-wide shared beliefs that guide them strategically in actions (Zehir et al., 2011). Innovations and capacity to innovate have positive influence on SMEs internationalization and competitive performance (Urbano et al., 2019; Radicic and Djalilov, 2019). Bose (2016) specifies that innovation is important to safeguard SMEs against ever-increasing competition and customer demand. However, to be competitive, companies with disruptive innovations require innovativeness to streamline internationalization. We propose that market orientation of disruptive innovation requires developing knowledge of the specific conditions that apply to the international market.

\section{The disruptive innovation market context}

Recent disruptive innovation research often refers to the work of Christensen and Bower (1996) and Christensen et al.'s (2015) discussions and definitions. For instance MartinezVergara and Valls-Pasola (2020) address the multitude of studies directed at disruptive 
MIP 39,5

\section{4}

innovation; Rasool et al. (2018) discuss the complexity before it reaches the international market and, in particular, how potentials can be exploited when entering new markets and finding new customers. This research considers companies as generic regarding size, characteristics and how these attributes influence internationalization. Robertson and Luiz (2019) suggest that disruptive innovation has better opportunities for internationalization by realizing the specific characteristics of the market. Knowledge and adaptation to the market's industrial changes, new products and technologies are examples that create better conditions for successful disruption. Robertson and Luiz (2019) propose that networking and business models need a global vision to capture technological development, institutional variables and market needs. Accordingly, the development process requires internal capacity based on developing market-oriented knowledge in helping companies to meet the specific needs of the market.

Market orientation of disruptive innovation faces several challenges. Christensen et al. $(1996,2015)$ discuss the constraints that innovations encounter when customers do not even know the innovations exist. According to Yu and Hang (2010), the disruption of old technology occurs when the new product displaces the incumbent product in the mainstream market. One disruptive example is cannibalization, which happens when both the old and the new product are sold by the same company (Schmidt and Druehl, 2008). The new product, however, gradually replaces the old product.

To avoid risks related to organizational constraints and path-resource dependencies, market-leading companies choose to stick with incumbent mainstream technology and can be unable to meet future customer needs (Christensen and Bower, 1996). Generally, smaller and hungry entrepreneurial companies take the risk of penetrating new markets with disruptive innovations, which Christensen et al. (2015) see as "a process whereby a smaller company with fewer resources is able to successfully challenge established incumbent businesses" ( $p$. 46). Smaller firms have advantages over large firms in the case of nontechnological innovations as they have less bureaucracy and more flexibility to adopt and react to changes (Radicic and Djalilov, 2019). Their flexibility offers competitive advantages, but the lack of technological and financial resources and marketing expertise hampers innovation capacity and internationalization (Radicic and Djalilov, 2019). Robertson and Luiz (2019) suggest that the complexity of disruptive innovation to successfully internationalize requires business models closely linked to the needs of the international market that capture technological development and institutional issues. To succeed, internal capacity is needed along with knowledge of the market's needs. We propose that SMEs with disruptive innovation need the support of an MOBM that promotes internationalization.

Schmidt and Druehl (2008) discuss the terminology of high-end and low-end encroachment to describe the contextual feature of the innovation on the market. Encroachment means that the disruptive innovation takes sales away from the incumbent innovation, which implies that these are competing with each other to satisfy customer needs. They suggest that understanding the contextual conditions of the innovation market can help companies determine the impact of the innovation relative to the market. However, according to Yu and Hang (2010), this high-end and low-end customer market division does not necessarily mean that the disruptive innovation replaces the incumbent one. Whether the high-low discussions concern the initial disruptive innovation per se or its impact on the entire customer-chain production to end users is still unclear. We propose that the MOBM needs to take into account the entire customer chain to streamline international disruption.

\section{Three dimensions of $M O$ intelligence}

$\mathrm{MO}$ as a concept is generic in that no specific consideration is given per se to which customer needs and conditions on international markets are to be met. According to Cadogan and 
Diamantopoulos (1995), structural and cultural variations in international markets can have moderating effects on $\mathrm{MO}$.

The MOBM focuses on three dimensions of knowledge development areas mediating the possibilities of SMEs to adapt to the new circumstances of the international business contexts: structural conditions (laws, rules, procedures), cultural circumstances (norms and values) and sustainability requirements (economic, social, and environmental conditions).

Examples of structural organizational conditions are the constraints companies experience in situations of change and uncertainty (DiMaggio and Powell, 1991). According to institutional research (DiMaggio and Powell, 1991), central actors such as the state, the professions or other dominant agents develop formal rules the companies need to comply with in internationalization. However, the degree of institutionalization varies, and for SMEs it is important to know laws and rules that prevail in the target market and the buying chain and how to follow them.

Cultural circumstances are central topics addressed in international market literature (Czinkota and Ronkainen, 2003). Hyder and Abraha (2008) argue that cultural dissimilarities may lead to differences in a firm's aims, management, operation and strategy implementation. Liao et al. (2011) noticed that cultures have strong effects on people's attitudes and ability to manage stakeholder relationships. Even if Czinkota and Ronkainen (2003) claim that the world is becoming homogenous, with a limited number of products with universal brand recognition, we argue that disruptive innovations are far from universal, making cultural dimensions a central issue in understanding international market conditions. Developing knowledge of different cultural issues and their impact on strategy formulation are important tasks in the SMEs' internationalization process (Bose 2016; Radicic and Djalilov, 2019).

The third dimension of knowledge concerns the necessity for SMEs to implement and integrate corporate social responsibility (CSR) and sustainability requirements in core activities to comply with market demands. Companies in B2B relationships are more or less forced to comply with sustainability standards and requirements imposed on them by international trade. This is particularly important when SMEs encounter business situations where they have to comply with sustainability requirements set by large purchasers as part of supply chains. Studies show that smaller companies have to rely on larger companies' business rules and struggle to survive by following codes of conduct (Sundström et al., 2016b). Suppliers are selected by buyers based on sustainability criteria, which means that business agreements depend on companies that can comply with the stated requirements (Ciliberti et al., 2008). CSR integration offers competitive advantages for SME suppliers meeting sustainability terms, while companies without codes of conduct risk losing corporate confidence and sending business deals to others. We propose that knowledge of structural, cultural and sustainability market variations can support firms with disruptive innovations to be successful on international markets.

\section{Research method}

The theoretical MOBM was developed as part of a research project funded by the European Union structural funds in Sweden. The purpose of that project was to investigate and test how the MOBM model can be applied to an action research project, as well as to evaluate how SMEs develop structural, cultural and sustainability knowledge of the market during the project. The theoretically anchored model was used for a year and a half between November 2017 and April 2019, to assess how four SMEs relate to the MO principles and later modified to reflect disruptive innovation market conditions. By following market intelligence principles in different work packages, the SMEs carried out three sets of tasks: gathering information about structural, cultural and sustainability aspects of the international market 
MIP

39,5

\section{6}

(developing awareness); disseminating this knowledge in their organization (developing innovativeness) and responding to information (developing market plans and strategies). The implementation of the MOBM required continuous interaction and feedback from the research group (seminars, workshops, on-site visits and interviews/observations), followed by evaluations/modifications. Data were collected continuously in collaboration with participating SMEs to evaluate and revise the business model.

\section{Selection of test SMEs}

The SMEs were selected with support of Triple Steelix 2.0, a cluster organization comprising about 700 steel-producing companies and manufacturers of mechanical equipment for metal forming and industrial IT, among other organizations, in the Dalarna and Gävleborg regions of Sweden. Triple Steelix works closely with the SMEs and has a clear conception of their operations, innovations and innovativeness. The companies were chosen based on the following criteria:

(1) Prior development of disruptive innovation with market-leading potential

(2) Potential for international growth

(3) Need and desire to gain international market knowledge and intelligence

(4) Acceptance of mutual exchanges between academic and business development, where the SME works toward its own development through action research.

(5) Inclusion in an active research project, where the companies accept that researchers participate, collect and use data as part of research activities.

Six SMEs were selected, but two of them had to quit the project due to workload and need for confidentiality. Four companies continued and followed the entire one-year project. Company A had developed a disruptive innovation in advanced sheet metal forming, company B in renewable energy systems, company $\mathrm{C}$ in measurement systems and radar technology and company $\mathrm{D}$ in metallurgical processes based on plasma technology. All companies understood that they needed overall market orientation knowledge of the customer chain to learn how their product could have a disruptive impact on their international market.

Triple Steelix evaluated and reported on the outcome to share experiences in their network. Besides the project group and Triple Steelix, an expert group followed, evaluated and reported on the implementation of the project. This collaboration contributed to both theoretical and practical knowledge that enriches all parties but also promoted regional business development in a broader sense.

Qualitative data were collected continuously throughout the project by conducting action research. This approach was suitable to handle a high level of interaction and complex data for theory development and conducting case studies (Eisenhardt, 1989; Yin, 2014). Furthermore, to manage parallel and interactive processes consisting of practical problems and theory development, the data needed to include several activities and networking interactions, actual learning processes and antecedents and consequences of activities undertaken by participants in the relational system (Doz, 2011). Sufficient time had to be allowed for the project and between the meetings to enable all involved actors to manage the change process related to their specific business context.

\section{Data collection}

The interaction approach was used for data collection, analysis and implementation of MOrelated knowledge areas in the companies. Project presentations including lectures, guest lectures, seminars and workshops were conducted. 
Major sources of the data include on-site visits and observations, individual interviews with the companies and SMEs' presentation of their homework. Observations were conducted at the firm premises to understand the production process, on-site to see how activities suggested in the work packages (WPs) function and devise improvements to the implementation. The SMEs allowed the researchers to visit their factories and committed full support during the research process, giving them confidence to start and complete the project within the stipulated time. Seven whole-day workshops took place in connection with the SMEs' presentations and completion of the introduced themes included in WPs. Individual interviews took place at company premises to investigate market challenges and opportunities regarding implementation of each WP. Seminars and workshops took place with other company members of Triple Steelix to exchange ideas on the development of the business model and to improve the companies' project implementation.

Data analysis fulfilled two purposes: to manage feedback practically and to write scientific papers (knowledge exchange). All meetings, both in-group and individual, were recorded and transcribed with the NVivo data-coding program, coded into different categories as learning outcomes and summarized into cases related to the knowledge process. Following Miles (1979), data were condensed by refining, iterating and revising the existing frameworks to suggest new leads for further data collection. This interactive approach was helpful for case identification, comparison and finding themes. According to Doz (2011) and Eisenhardt and Graebner (2007), rich qualitative data, which this study is expected to generate, helps to support theory development and models.

Because the SMEs have developed disruptive innovations critical to their success, all data are anonymous. The companies had the opportunity to comment on research data collected to ensure it was reliable and handled with care.

\section{The MOBM project}

Developing MO intelligence constituted the core element of the process, in which researchers guided the SMEs in working with solutions to identify critical knowledge issues in the international market context. This research approach contributed to new insights for the researchers to analyze, evaluate and modify the MOBM on the notified experiences from the chosen SMEs. By combining companies' input with academic knowledge, the exchange of ideas could take place as part of a dynamic and interactive process. The project involved action research, which is process-oriented and interactive by nature, allowing for participatory collaboration between SMEs, researchers and other involved partners (Svensson and Nielsen, 2006). Figure 1 shows the MOBM process in WPs that was used to assess the development and implementation of market intelligence in the participating SMEs from a disruptive innovation perspective.

To work systematically with the project, four WPs were developed. The WPs were planned and formulated in concrete tasks considering MO intelligence topics, followed by group discussion and the SMEs' expectations of the project. Each WP dealt with a concrete MO-related knowledge theme relating to the development and evaluation of the MOBM and the aim of the project. The themes encompassed SMEs' intelligence development with their own work and practices related to cultural, structural and sustainability elements, as described below.

\section{The MO learning and intelligence development process}

The MOBM consists of four interactive research and development WPs, with two meetings in each (except for one full-day evaluation in WP 4). The WP1 to WP3-meetings aimed at SMEs describing the current situation as a basis for gap analysis, collecting information about the 
MIP

39,5

678
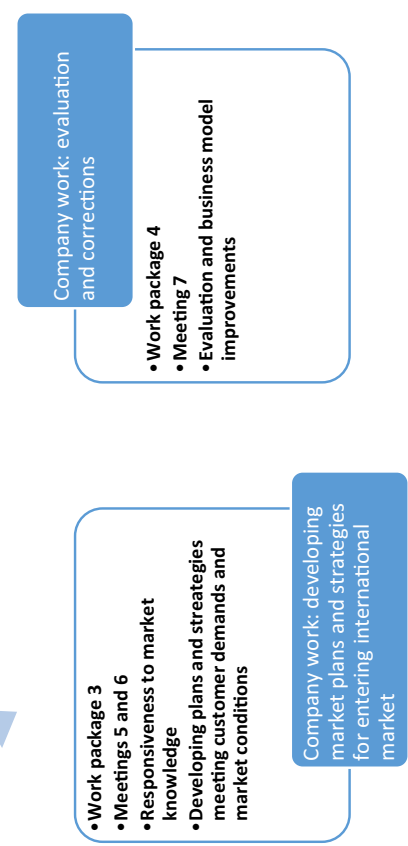

Figure 1.

Theoretical marketoriented business model (MOBM) for internationalization
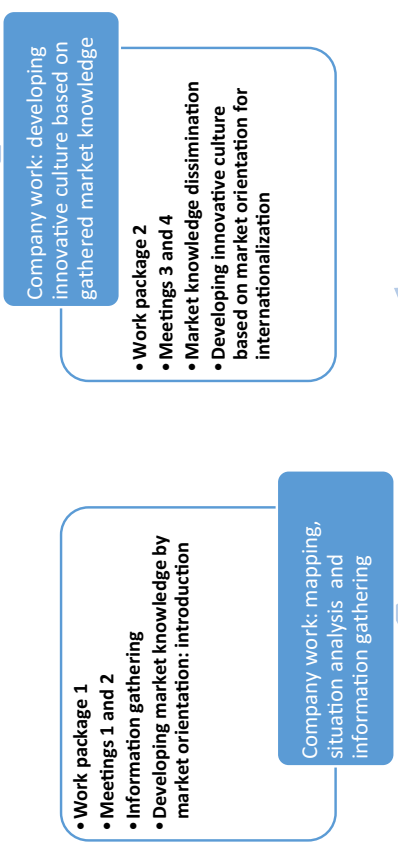
targeted market, disseminating it in the organization to build innovation capacity and develop strategies for internationalization. In the meetings, the researchers introduced an $\mathrm{MO}$ theme for the companies to work with and present in the next meeting. In the next meeting, a new theme was introduced, and so on. The companies worked with questions such as: What do we know about the market today, and what areas do we need to gather information about? (WP1); how can we disseminate and implement new information in the organization? (WP2); what strategies do we need to develop to reach the market? (WP3) and Given what we have done - what have we learned and what needs to improve? (WP4). This intelligence development process, starting with the introduction of an MO theme, continuing with working on their own and the sharing of experiences in the group, continued throughout the project. Problem formulation, ensuring that the SMEs correctly identified the MO problems they face with their products, took place in direct collaboration between the SMEs and the researchers.

To get an overview of the SMEs' difficulties with MO work and what scientific support the researchers could offer, four of the meetings were organized at the companies' premises. During the process, the SME participants were encouraged to write down experiences they obtained from the implementation of the project. The researchers also assessed how the collected data could be used for scientific publication and conducting case studies for higher education.

\section{WP1. Developing market knowledge by market orientation - introduction and gathering of market information}

Initially the participants were introduced to how the project was organized, knowledge areas of MOBM (cultural, structural and sustainability knowledge aspects) related to the international market and expectations of them and the researchers as a reciprocal contract.

Between meetings 1 and 2, participants were assigned to carry out situation analysis with questions about how they work toward the international market. Traditional MO research assumes that companies are engaged in market inventory and market research activities. This study instead assumed that SMEs lack knowledge of the current situation and market conditions and need to conduct market surveys as a foundation. The four companies had different disruptive innovations, experiences and needs for market intelligence development. In the next meetings, they shared experiences with each other, adding to their common learning. The goal of situation analysis was that the SMEs should understand current obstacles and opportunities in the international market. This mapping showed them the need for information gathering (see Kohli and Jaworski, 1990) about the conditions in the international market.

Between meetings 2 and 3, the SMEs were asked to collect new information about the prioritized international market related to customer needs and market conditions.

The WP1 meetings showed that SMEs differ in how they define the scope and size of the market. All four SMEs were highly technology-oriented and had a vague idea of which market to prioritize. The discussions concerned not only the internationalization of their primary product market but also conditions to meet related to their customers' businesses, products and market needs - the customer chain.

Lesson learned from WP1: market orientation of disruptive innovations encompasses the complexity of the customer-chain market.

\section{WP2. Developing an innovative culture of intelligence based on market orientation for internationalization}

Based on the learning from the two meetings and each SME's own work in WP1, the project continued with WP2 - introducing how to develop cross-sectional intelligence by knowledge 
MIP

39,5

\section{0}

dissemination (Kohli and Jaworski, 1990) in SME organizations. According to Narver and Slater (1990), interfunctional coordination and knowledge sharing can contribute to long-term superior value for the customer by creating a culture characterized by innovativeness. Effective and strategic internal knowledge dissemination can help companies become more proactively market-driving rather than being driven reactively to meet market demands (O'Cass and Ngo, 2007). The goal of WP2 was to encourage SMEs to disseminate knowledge of the international market within their organization in order to work strategically, in a coordinated fashion and innovatively toward the same goals.

In WP2, the SMEs had to disseminate information about the international market related to cultural, structural and sustainability aspects. Business-related aspects were about identifying which customers, suppliers and competitors they face in the international market. Cultural aspects included developing intelligence related to business culture and the international market culture, as well as discussing how to meet these aspects in the internationalization process. Structural aspects included formal and legal requirements that the companies needed to initiate learning processes to manage. To this end, they met international trade experts and lawyers. The sustainability aspects concerned issues related to how they can work to meet the United Nations 2030 goals, buyer compliance and corruption issues. During this WP, they were able to continue to gather market information.

The WP2 meetings showed that the companies had different degrees of innovativeness for working with the internal dissemination of market knowledge. Company A arranged many internal meetings, which contributed to effective knowledge dissemination; company B experienced problems with too many egos; company $\mathrm{C}$ chosed to keep all market knowledge within top management and company $\mathrm{D}$ was project-oriented and had problems disseminating new information internally.

Lessons learned from WP2: market orientation of disruptive innovations includes several organizational coordination challenges to develop internal innovativeness that meets market needs and requirements.

\section{WP3. Developing market plans and strategies for meeting customer demands and market conditions}

As Kohli and Jaworski (1990) found, a company's responsiveness to collected and disseminated market information reflects its tendency, flexibility and ability to act successfully based on knowledge of what customers want and require (see also Hyder, 2016; Sundström et al., 2016a). According to the MOBM, the SMEs should meet international market demands by developing responsiveness strategies based on data dissemination. This step is close to research, drawing attention to how companies use knowledge by planning and developing market strategies. According to Aaker and McLoughlin (2010), global innovations can be sourced anywhere, but SMEs' innovations required basic knowledge and strategies aimed at the customer-chain market to be disruptive.

Based on the knowledge development in WP1 and WP2, the goal of WP3 was for the SMEs to develop market plans, strategies and initiatives to meet international customer demands. The different (dis)advantages of different marketing strategies were discussed related to the specific business context. The researchers explained different market strategies, for instance those of Aaker and McLoughlin (2010), and through their own work the SMEs could evaluate which suited their product and market conditions. The project showed that this part of the knowledge process was most difficult for SMEs to handle. Because the SMEs were still mainly technology-oriented in discussions, the researchers had to encourage them to understand how to develop plans to meet market needs strategically.

Lesson learned from WP3: the biggest challenge for SMEs with disruptive innovation is to take the responsiveness step from knowledge dissemination to practical action. 
WP4. Evaluation and business model improvements

The project involved continuous evaluations through the participants' feedback on their own work and group discussions. The researchers had to modify the MOBM according to the knowledge needs identified during the project. The companies considered that they had reached higher maturity during the process. In particular, they appreciated the exchange of experience and knowledge that occurred between them and other participating SMEs. In sum, the work with MOBM contributed to theoretical knowledge and structure, and the exchange of experience contributed to practical guidance for SMEs.

Lesson learned from WP4: The developed MOBM is well placed to structure and guide SMEs' work on internationalization, but more internal and external initiatives are required to disseminate knowledge for responsiveness and strategic action.

\section{Discussion}

The work with the MOBM shows that stronger incentives and market orientation tools are required for SMEs with disruptive innovation to

(1) Review the customer chain involved to orient themselves to the market and internationalize disruptive innovations

(2) Coordinate internal knowledge and innovativeness work to get companies moving toward the same goal and

(3) Provide external support to take the step from internal knowledge development to entering the international market in practice.

\section{Customer chain challenges}

Figure 2 specifies the process the SMEs follow to gain knowledge of the international buyer chain and implement effective disruptive innovation.

Figure 2 suggests that the SMEs need to have both high-end and low-end encroachment on incumbent innovation with international buyers to create disruptive innovation. For each part of the model, there is a need to identify the need for disruptive innovation within the buying chain of the customer, which makes the process complicated to execute. As an example, company A sells a machine for advanced sheet metal forming to companies that produce three-dimensional sheet metal. That sheet metal should in turn be adapted to their business buyer who uses it in car manufacturing and in turn needs to have knowledge of how

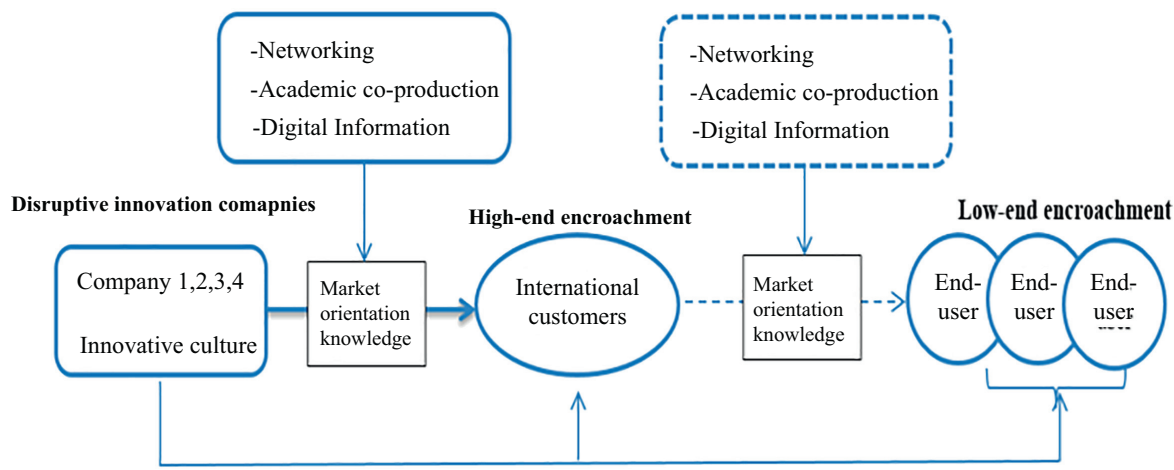

Developing international market knowledge: culture, structure and sustainability
Marketoriented business model

681 
MIP

39,5

682

end users (car buyers) regard the innovation. Company A is highly aware that it needs to influence the entire customer chain to have a disruptive innovation breakthrough on the international market, as well as that the CEO needs to devote more time to identifying and meeting the needs of customers at several levels.

The traditional MO intelligence perspective does not address how markets differ and meet varying customer needs. The theoretical discussions thus assume that information gathering and cross-sector dissemination will lead to responsiveness, influencing company performance (Kohli and Jaworski, 1990). If this interrelationship is weak, it is assumed that moderating factors can have direct impact on the MO-performance relationship (Liao et al., 2011). The four SMEs have experienced obstacles in commercializing their innovations internationally, due to a lack of market-oriented intelligence and customer contacts related to specific product innovation (Liao et al., 2011; Zehir et al., 2011; Radicic and Djalilov, 2019). But the complexity of including customers and their buyer chains with different market demands and conditions (Christensen et al., 2015) makes it difficult for SMEs to know which market information to prioritize. The study finds that SMEs need to carefully go through the customer chain to orient themselves to the market and internationalize their disruptive innovations. Theoretically, this means that research relating to $\mathrm{MO}$ of disruptive innovations needs to be expanded to include several levels of the customer chain.

\section{Internal knowledge coordination and innovativeness}

MO research is commonly linked to the development of innovativeness and seen as the process of achieving new thinking, openness to new ideas and the ability to learn and develop intelligence (Hult et al., 2004). This process is crucial to gaining customer acceptance of the innovation (Menguc and Auh, 2008). Innovativeness may arise based on a willingness and commitment to master the latest products or technological services (Liao et al., 2011; Urbano et al., 2019). For successful internationalization, it is not enough to develop an innovation; SMEs also need internal expertise and openness to meet international requirements (Bose, 2016; Radicic and Djalilov, 2019) and develop knowledge of the market, for instance by market research, advertising and promotion (Miller and Friesen, 1978), which requires strategic planning and coordination (Hult et al., 2004; Bose, 2016). It is important to take advantage of the firm's ability to develop strong internal knowledge capacity, resource coordination, appropriate policy formulation and innovativeness to achieve business goals (Radicic and Djalilov, 2019). MO research is commonly normative and overlooks that SMEs often develop innovations but lack necessary resources and capacity to disseminate knowledge within the organization.

The study shows that SMEs face internal barriers to developing innovativeness including weak coordination (many egos), development being a top management matter, too strong a focus on technology development and devoting most time and interest in the organization to existing projects. Company A was most successful in initiating knowledge of dissemination meetings and dividing production into different product groups, where employees worked with different marketing strategies. The study confirms that there is a weak link between innovation development and required innovativeness due to a lack of time for necessary coordination. The disruptive feature of innovation makes it difficult for an organization to internally disseminate the proper market knowledge about the innovation demands of the buyer and its buying chain. Theoretically, this study shows that internal processes are the most critical aspect for SMEs in developing disruptive international market intelligence. Most attention of all SMEs has so far been paid to technical and production-related processes.

\section{External support to manage the gap from intelligence development to practice}

The third stage in an MO intelligence perspective is to develop responsiveness to gathered and disseminated knowledge (Kohli and Jaworski, 1990). In the project, the internal shortcomings 
addressed in WP2 also affected the SMEs' ability to develop plans and strategies and hence effectively meet customer needs in the international market (Urbano et al., 2019; Bose, 2016). The shortcomings prevented them from developing what Narver $e t$ al. (2004) frame as an insideout process, where they could drive the market. While market intelligence theoretically assumes links between data collection, data dissemination and responsiveness (Kohli and Jaworski, 1990), the study shows that the weakest link is between dissemination of information and applying it strategically in relation to the market. The studied SMEs understood customerchain businesses fairly well but lacked both internal knowledge-based strategies/routines and external support to enter into the international market.

\section{Conclusion}

This study dealt with three research issues relating to (1) the development and evaluation of a market-oriented business model (MOBM), (2) acquiring knowledge on marketing of disruptive innovation and (3) applying the business model to manage SMEs' challenges in the internationalization of disruptive innovations. The model was developed from a market orientation perspective by integrating four work packages to gather market intelligence and assess the suitability of the model. MO research assumes that there is an intermediate link among the three market intelligence dimensions: information gathering, knowledge dissemination and responsiveness. Although multiple studies have been performed to measure the relationship among the different dimensions, they show different results of which factors have the weakest link in developing market intelligence. This study theoretically contributes to showing that the links among the dimensions cannot be taken for granted and/or explained through studies of multiple meditator and moderator effects. SMEs with disruptive innovation need support from business models to develop (1) knowledge throughout the entire customer chain, (2) the ability to disseminate and build up market knowledge internally and (3) strategies to apply the knowledge in practice. Application of the MOBM shows that it provides robust market orientation support to SMEs in dealing with these three barriers to managing the internationalization of disruptive innovation.

This developed model applies MO intelligence principles to develop SMEs' knowledge for internationalization. This approach fits better with SMEs' resource constraints and compensates for their inability to gather direct experience from the marketplace. The strength of the model lies in its dynamic nature and allowing continuous interaction with the market and actors of buyer chains to meet market requirements. This study highlights the role of $\mathrm{MO}$ in dealing with the complexity of disruptive innovation internationalization. This finding is in line with Robertson and Luiz (2019), who stress the urgency of business models closely linked to the needs of the international market to integrate technological development and institutional issues for internationalization of disruptive innovation.

This research has shown that the SME internationalization process needs to be anchored and supported in business models that can handle the interaction that exists between external activities and internal knowledge development, and the companies must apply that generated experience and competence in their own activities aimed at the international market. The SMEs in our study have an excessive focus on technological and economic issues. Moreover, they face problems with internal coordination to effectively disseminate market knowledge. Bose (2016) and Radicic and Djalilov (2019) have observed that SMEs are weak in generating and organizing internal knowledge to support internationalization. We argue that internal knowledge and external activities must go hand in hand to have a positive effect on market orientation of disruptive innovation.

\section{Implications and future research directions}

This study has offered several theoretical contributions by developing a MOBM for SMEs' internationalization. First, Kohli and Jaworski (1990) and Narver and Slater (1990) highlight 
MIP

39,5

\section{4}

information dissemination and internal coordination for developing MO intelligence. They take this issue for granted and therefore do not address how an organization can generate this knowledge. Christensen et al. (2015), on the other hand, introduce learning as an important factor for disruptive innovation internationalization without emphasizing a market focus. This study filled these gaps by introducing and applying market-oriented learning for SMEs' internationalization of disruptive innovation. Second, whereas Kohli and Jaworski (1990) focused internal dissemination of information, this study has extended the MO technique to cover the whole internationalization process. The MOBM suggests that organizational competence and disruptive innovation are not enough: an SME needs a total understanding of the buyer chain to satisfy the needs in that link. Third, MO's intelligence perspective does not consider SME internationalization of disruptive innovation. In line with Robertson and Luiz (2019) and Rissanen et al. (2019), this study has developed business-related knowledge packages connecting with structural conditions, cultural circumstances and sustainability requirements to supplement the MO perspective and strengthen SMEs' support efforts for internationalization. Fourth, development, evaluation and implementation have jointly reinforced the model to offer a unique opportunity in following the knowledge development process. Fifth, emphasis on market focus rather than concentrating on technological competence offers a new challenge for SMEs with disruptive innovation. Lastly, from a methodological viewpoint, this study allows evaluation and modification of the model by adding company experiences over the project period. Theory development via qualitative data is common (Yin, 2014; Eisenhardt, 1989), but using a company perspective for theoretical knowledge generation is rare. Theoretically, this study contributes to research in market orientation by showing that several international markets are affected, which is specifically clear in the context of disruptive innovations.

There are some managerial implications. First, managers can effectively use the MOBM because it has been developed for SMEs from the perspective of internationalization. Second, managers can develop their strategies and business models in close collaboration with academics. A business model directed toward fulfilling customer-chain demands will be helpful in reducing the risks SMEs face in internationalization. This study provides a concrete example how business and universities can work together for mutual benefit. Third, this study suggests that managers need to adopt market orientation from the beginning to develop a joint culture of technological and market expertise. Finally, SME managers need to have a total view of the situation where not only buyers but even the buyer chains are integrated for successful marketing of disruptive innovation.

Importance of the buyer chain in understanding markets has been discussed in this study without going into depth about the interactions between chain participants. Further studies could focus on this issue and examine how buyer chains function at different levels and support the internationalization of disruptive innovation. The business model could also be tested with larger firms, focusing on disruptive innovation internationalization. The MOBM can be used by researchers to support SMEs' development of market knowledge, followed by a traditional MO approach to study the model's impact on SMEs' internationalization. This type of model could be applied to compare differences between industries in future research projects. This type of study can give new insight into the generation and practice of market intelligence in relation to internal knowledge and external activities. Further market-oriented business models could be developed and tested for service-based disruptive innovation.

\section{References}

Aaker, D.A. and McLoughlin, D. (2010), Strategic Market Management - Global Perspectives, John Wiley \& Sons, Chichester, West Sussex. 
Ahmadi, Z. and Sundström, A. (2017), "The market intelligence impact on strategic performance in declining markets", International Journal of Applied Business and Economic Research, Vol. 15 No. 15 , pp. 457-473.

Bose, T.K. (2016), "Critical success factors of SME internationalization", Journal of Small Business Strategy, Vol. 26 No. 2, pp. 87-109.

Cadogan, J.W. and Diamantopoulos, A. (1995), "Narver \& Slater, Kohli \& Jaworski and the market orientation construct: integration and internationalization", Journal of Strategic Marketing, Vol. 2 No. 1, pp. 41-60.

Christensen, C.M. and Bower, J.L. (1996), "Customer power, strategic investment and the failure of leading firms", Strategic Management Journal, Vol. 17, pp. 197-218.

Christensen, C.M., Raynor, M.E. and McDonald, R. (2015), "What is disruptive innovation?", Harvard Business Review, December, pp. 44-53.

Ciliberti, F., Pontrandolfo, P. and Scozzi, B. (2008), "Investigating corporate social responsibility in supply chains: an SME perspective", Journal of Cleaner Production, Vol. 16, pp. 1579-1588.

Cowden, B.J. and Alhorr, H.S. (2013), "Disruptive innovation in multinational enterprises", Multinational Business Review, Vol. 21 No. 4, pp. 358-371.

Czinkota, M.R. and Ronkainen, I.A. (2003), "An international marketing manifesto", Journal of International Marketing, Vol. 11 No. 1, pp. 13-27.

DiMaggio, P.J. and Powell, W.W. (1991), The New Institutionalism in Organizational Analysis, University of Chicago Press, Chicago, IL.

Doz, Y. (2011), "Qualitative research for international business", Journal of International Business Studies, Vol. 42 No. 5, pp. 582-590.

Eisenhardt, K.M. (1989), "Agency theory: an assessment and review”, Academy of Management Review, Vol. 14, pp. 57-74.

Eisenhardt, K.M. and Graebner, M.E. (2007), "Theory building from cases: opportunities and challenges", Academy of Management Journal, Vol. 50 No. 1, pp. 25-32.

Hult, T., Hurley, R. and Knight, G.A. (2004), "Innovativeness: its antecedents and impact on business performance", Industrial Marketing Management, Vol. 33 No. 5, pp. 429-438.

Hyder, A. (2016), "Market orientation in a non-profit organisation", World Review of Entrepreneurship Management and Sustainable Development, Vol. 12 No. 4, pp. 414-432.

Hyder, A.S. and Abraha, D. (2008), "Institutional factors and strategic alliances in Eastern and central Europe", Baltic Journal of Management, Vol. 3 No. 3, pp. 289-308.

Johanson, J. and Vahlne, J.-E. (2009), “The Uppsala internationalization process model revisited: from liability of foreignness to liability of outsidership", Journal of International Business Studies, Vol. 40 No. 9, pp. 1411-1431.

Kohli, A.K. and Jaworski, B.J. (1990), "Market orientation: the construct, research propositions, and managerial implications", Journal of Marketing, Vol. 54 No. 4, pp. 1-18.

Liao, S.-H., Widowati, P.A.R. and Hu, D.-C. (2011), "A study on the customer-based brand equity of Taiwanese and Indonesian teenagers for a global brand", African Journal of Business Management, Vol. 5 No. 34, pp. 12929-12938.

Martinez-Vergara, S.J. and Valls-Pasola, J. (2020), "Clarifying the disruptive innovation puzzle: a critical review", European Journal of Innovation Management, Vol. 1, ISSN: 1460-1060, doi: 10. 1108/EJIM-07-2019-0198.

Menguc, B. and Auh, S. (2008), "The asymmetric moderating role of market orientation on ambidexterity-firm performance relationship for prospectors and defenders", Industrial Marketing Management, Vol. 37 No. 4, pp. 455-470.

Mesic, Ž., Molnár, A. and Cerjak, M. (2018), “Assessment of traditional food supply chain performance using triadic approach: the role of relationships quality", Supply Chain Management: An International Journal, Vol. 23 No. 5, pp. 396-411. 
MIP

39,5

686
Miles, M. (1979), "Qualitative data as an attractive nuisance: the problem of analysis", Administrative Science Quarterly, Vol. 24, pp. 590-601.

Miller, D. and Friesen, P. (1978), "Archetypes of strategy formulation", Management Science, Vol. 24, pp. 921-933.

Narver, J.C. and Slater, S.F. (1990), "The effect of a market orientation on business profitability", Journal of Marketing, Vol. 54 No. 4, pp. 20-35.

Narver, J.C., Slater, S.F. and MacLachlan, D.L. (2004), "Responsive and proactive market orientation and new product success", Journal of Product Innovation Management, Vol. 21, pp. 334-347.

O'Cass, A. and Ngo, L.V. (2007), "Market orientation versus innovative culture: two routes to superior brand performance”, European Journal of Marketing, Vol. 41 Nos 7/8, pp. 868-887.

Radicic, D. and Djalilov, K. (2019), "The impact of technological and non-technological innovations on export intensity in SMEs", Journal of Small Business and Enterprise Development, Vol. 26 No. 4, pp. 612-638.

Rasool, F., Koomsap, P., Afsar, B. and Panezai, B.A. (2018), “A framework for disruptive innovation”, Foresight, Vol. 20 No. 3, pp. 252-270.

Rissanen, T., Ermolaeva, L., Torkkeli, L., Ahi, A. and Saarenketo, S. (2019), "The role of home market context in business model change in internationalizing SMEs", European Business Review, Vol. 32 No. 2, pp. 257-275.

Robertson, N. and Luiz, J.M. (2019), "Exploiting emerging market complementarities: delayed, then accelerated internationalisation in a technology EMNE", Multinational Business Review, Vol. 27 No. 1, pp. 54-76.

Schmidt, G.M. and Druehl, C.T. (2008), "When is a disruptive innovation disruptive?", Journal of Product Innovation Management, Vol. 25, pp. 347-369.

Slater, S.F. and Narver, J.C. (1998), "Customer-led and market-oriented: let's not confuse the two", Strategic Management Journal, Vol. 19 No. 10, pp. 1001-1006.

Sundström, A., Ahmadi, Z. and Hyder, A. (2016a), "Market and innovation orientation typology: proposition and illustrations", Marketing Intelligence and Planning, Vol. 34 No. 3, pp. 376-393.

Sundström, A., Sammalisto, K., Hyder, A.S. and Chowdhury, E.H. (2016b), "CSR implementation strategy constraints in emerging market supply chain context - Bangladesh garment industry experience", International Journal of Applied Business and Economic Research, Vol. 14 No. 13, pp. 9041-9062.

Svensson, L. and Nielsen, K.A. (2006), Action Research and Interactive Research: Beyond Practice and Theory, Shaker Publishing, Maastricht.

Urbano, D., Turro, A. and Aparicio, S. (2019), "Innovation through R\&D activities in the European context: antecedents and consequences", Journal of Technology Transfer, Vol. 45, pp. 1-24, doi: 10.1007/s10961-019-09752-x.

Yin, R.K. (2014), Case Study Research: Design and Methods, 4th ed., Sage, Los Angeles, CA.

$\mathrm{Yu}$, D. and Hang, C.C. (2010), "A reflective review of disruptive innovation theory", International Journal of Management Reviews, Vol. 12, pp. 435-452.

Zehir, C., Altindag, E. and Acar, A.Z. (2011), "The effects of relationship orientation through innovation orientation on firm performance: an empirical study on Turkish family- owned firms", Procedia Social and Behavioral Sciences, Vol. 24, pp. 896-908.

\section{Corresponding author}

Agneta Sundström can be contacted at: awd@hig.se

For instructions on how to order reprints of this article, please visit our website:

www.emeraldgrouppublishing.com/licensing/reprints.htm

Or contact us for further details: permissions@emeraldinsight.com 